\title{
David Oliver: Vaccination sceptics are immune to debate
}

\section{David Oliver consultant in geriatrics and acute general medicine}

Berkshire

In 2018 we learnt that rates of vaccination against measles, mumps, and rubella (MMR) in under 10s fell in the UK for the sixth consecutive year. ${ }^{1}$ From 2010 to 2017 an estimated half a million children missed their MMR vaccination. ${ }^{2}$

The UK's MMR coverage is now well below the 95\% recommended by the World Health Organization to ensure effective herd immunity. Unicef reported that over 21 million children a year worldwide miss their measles vaccination. The picture is similar for several vaccine preventable conditions. ${ }^{3}$ WHO announced that, from 2017 to 2018 , reported measles cases in Europe tripled. ${ }^{4}$ The United Nations reported that cases had quadrupled worldwide. ${ }^{5}$ Experts such as Helen Bedford, writing for the BBC, set out links between declining uptake of vaccination and the rise in outbreaks. ${ }^{6}$

\section{Pseudoscience}

Academic and journalistic analyses of vaccine hesitancy and falling uptake have highlighted the role of social media activism and pseudoscience in citing vaccination as harmful, unproved, and behind the rise in conditions such as autism. ${ }^{7-11}$ Blame has also been laid at the door of right wing populism, with its distrust of government, scientific experts, and professionals. The arguments focus on individual liberty and parents' rights to make decisions for their own children. ${ }^{10}$

André Spicer, professor of organisational behaviour at the Cass Business School at City, University of London, argued in the Guardian that "scare tactics" and "heavy handed warnings" would not improve vaccination rates. ${ }^{12}$ A variety of approaches to better information and involving families in benefits was more likely to work for "hesitant parents." Paul Ward, a public health professor, has argued that blaming parents rather than seeking to understand their fears is counterproductive. ${ }^{13}$

Persuading individual parents is one thing. But trying to debate with the more determined anti-vaccination activists can be a futile endeavour, not played by the rules healthcare experts are used to.

Every scientific paper in support of the cause (whatever its quality) and every commentator sympathetic to the cause (expert or not) is selectively harvested and cited. Allegedly hidden harms and risks of vaccination are highlighted. If you're not a genuine content expert it's impossible to wade through each individual source to appraise it or understand its limitations. If you really are a content expert, steeped in the science and leadership of mass vaccination-or an official body, from Public Health England through to WHO or the UN-you'll be labelled as being close to (and influenced by) the vaccine manufacturers, and the impartiality of your advice will be questioned.

Reports of outbreaks and rising infections will be dismissed: "How many of those cases were actually verified?" The severity of the disease we're trying to prevent will also be questioned. Measles and other preventable childhood infections can kill or bring serious long term damage and disability, but these consequences will be minimised to suit the cause. You'll be told that not all vaccinated people mount a sustained immune response (which is precisely why we need a high uptake for herd immunity).

Don't be surprised if your defence of mass vaccination against refuseniks leads to attacks on social media or impassioned private correspondence. If you push back, the whole cycle will start again.

The idea of children developing natural, normal immunity through exposure to infections will be romanticised. Arguments about the collective societal need to vaccinate our own children so that we don't put other children at risk will be either ignored or represented as a callous attack on parents and dismissal of their concerns-potentially a bad look for doctors and nurses, even when acting for a greater cause. And suggestions that vaccine refusers are putting their own children at risk will be used to make those doctors look even worse.

\section{Responding to arguments}

When it comes to high emotional stakes played out in public, it's a roughly equal contest: reports and shocking pictures of children with serious, vaccine amenable infections versus harrowing stories from parents of children who were fine until 
vaccination but whose ill health or disability coincided with it. And pointing out that a correlation doesn't prove causation will find you further wearing the tag of a patronising, number crunching technocrat divorced from the realities that real people just know, in their bones.

WHO has published guidelines on How to Respond to Vocal Vaccine Deniers in Public. ${ }^{14}$ Using data, evidence, and expert consensus to combat arguments that come from the gut and the heart isn't an easy road. Perhaps it's better to focus on effective methods of raising vaccination rates and accepting that, in some arguments, you either can't win or will only be made to look bad if you do.

Competing interests: See www.bmj.com/about-bmj/freelance-contributors.

Provenance and peer review: Commissioned; not externally peer reviewed.

1 Owoseje T. Number of children in England being vaccinated reaches six-year low. Independent 2018 Sep 18. https://www.independent.co.uk/news/health/uk-childrenvaccinations-nhs-decline-measles-meningitis-a8543061.html.

2 More than 500000 UK children unprotected against measles after missing vaccinations. ITV News 2019 Apr 25. https://www.itv.com/news/2019-04-25/vaccine-rejection-publichealth-timebomb-nhs-head-warns/.

3 Humphreys $\mathrm{O} .21$ million children miss first dose of measles vaccine every year. New Sci 2019. https://www.newscientist.com/article/21-21-million-children-miss-first-dose-ofmeasles-vaccine-every-year/

4 Measles cases in Europe tripled last year, WHO says. BBC News 2019 Feb 7. https:// www.bbc.co.uk/news/health-47157020.
Measles cases quadruple globally in 2019, says UN. BBC News 2019 Apr 16. https:/ www.bbc.co.uk/news/health-47940710.

6 Bedford H. Measles: how a preventable disease returned from the past. BBC News 2019 Apr 5. https://www.bbc.co.uk/news/health-47800438.

7 Evrony A, Caplan A. The overlooked dangers of anti-vaccination groups' social media presence. Hum Vaccin Immunother2017;13:1-2. https://www.ncbi.nlm.nih.gov/pmc/articles/ PMC5489284/. 10.1080/21645515.2017.1283467 28406737

8 Cohen $E$. Anti-vaxers are winning the war on social media. What's the CDC going to do about it? CNN 2019 Apr 12. https://edition.cnn.com/2019/04/12/health/cdc-vax-advisers/ index.html.

9 Smith TC. Vaccine rejection and hesitancy: a review and call to action. Open Forum Infect Dis 2017;4:ofx146 (published online 2017 Jul 18). 10.1093/ofid/ofx146. https://www.ncbi. nlm.nih.gov/pmc/articles/PMC5597904/.

10 Adler JR, Hussain A, Ali S, Ahmed M, Hussain S, Muacevic A. The anti-vaccination movement: a regression in modern medicine. Cureus 2018;10:e2919 (published online 2018 Jul 3). 10.7759/cureus.2919. https://www.ncbi.nlm.nih.gov/pmc/articles/PMC6122668/

11 Boseley S. Vaccine scepticism grows in line with rise of populism —study. Guardian 2019 Feb 25. https://www.theguardian.com/world/2019/feb/25/vaccine-scepticism-rises-in-linewith-votes-for-populists-study-finds.

12 Spicer A. Measles is on the march again-but scare tactics won't improve vaccination rates. Guardian 2019 Apr 26. https://www.theguardian.com/commentisfree/2019/apr/26/ measles-vaccinations-immunisation-parents-children.

13 Ward P. Labelling anti-vaxxers as bad parents doesn't help —it just leads to more distrust in science. Guardian 2019 May 13. https://www.theguardian.com/commentisfree/2019/ may/13/labelling-anti-vaxxers-as-bad-parents-doesnt-help-it-just-leads-to-more-distrustin-science.

14 World Health Organization. Best practice guidance: how to respond to vocal vaccine deniers in public. 2017. http://www.euro.who.int/_data/assets/pdf_file/0005/315761/Bestpractice-guidance-respond-vocal-vaccine-deniers-public.pdf.

Published by the BMJ Publishing Group Limited. For permission to use (where not already granted under a licence) please go to http://group.bmj.com/group/rights-licensing/ permissions 